\title{
The Social Acceptance of Collecting and Utilizing Personal Information in Smart Cities
}

\author{
Yuho Shimizu ${ }^{1, *(\mathbb{D}}$, Shin Osaki ${ }^{2}$, Takaaki Hashimoto ${ }^{3}$ and Kaori Karasawa ${ }^{1}$ \\ 1 Graduate School of Humanities and Sociology, The University of Tokyo, Tokyo 1130033, Japan; \\ karasawa@l.u-tokyo.ac.jp \\ 2 Graduate School of Frontier Sciences, The University of Tokyo, Tokyo 1138656, Japan; \\ osaki@edu.k.u-tokyo.ac.jp \\ 3 Faculty of Sociology, Toyo University, Tokyo 1128606, Japan; hshmtsp@gmail.com \\ * Correspondence: yuhos1120mizu@gmail.com
}

Citation: Shimizu, Y.; Osaki, S.; Hashimoto, T.; Karasawa, K. The Social Acceptance of Collecting and Utilizing Personal Information in Smart Cities. Sustainability 2021, 13, 9146. https://doi.org/10.3390/ su13169146

Academic Editor: Fanli Jia

Received: 16 July 2021

Accepted: 13 August 2021

Published: 16 August 2021

Publisher's Note: MDPI stays neutral with regard to jurisdictional claims in published maps and institutional affiliations.

Copyright: (c) 2021 by the authors. Licensee MDPI, Basel, Switzerland. This article is an open access article distributed under the terms and conditions of the Creative Commons Attribution (CC BY) license (https:// creativecommons.org/licenses/by/ $4.0 /)$.

\begin{abstract}
In recent years, active efforts to implement smart cities have increased worldwide. In smart cities, a large amount of personal information is captured, and urban development is based on these data. In Japan, implementations of smart cities continue to gain momentum, but the issue of social acceptance has become apparent, as smart cities are not fully accepted by citizens because of concerns about data leaks and misuse of personal information. This study examines the social acceptance of collecting and utilizing personal information in smart cities in relation to a variety of factors such as trust and perceptions of risk, justice, benefit, and necessity. An online survey was conducted wherein participants $(N=568)$ were presented with a vignette depicting an overview of a typical smart city. The results of structural equation modeling showed that perceived justice was positively related to trust and trust was negatively related to perceived risk and positively related to perceived benefit and necessity. Trust, perceived benefit, and perceived necessity were significantly related to social acceptance, with trust having the greatest relationship. The model obtained in this study contributes to practical efforts for the implementation of smart cities, and future directions are discussed.
\end{abstract}

Keywords: smart city; social acceptance; structural equation modeling; Japan

\section{Introduction}

\subsection{Background}

In recent years, there has been a growing movement toward the implementation of smart cities around the world. Specifically, the development of sustainable cities using artificial intelligence and big data is being promoted to solve various social issues worldwide, including environmental problems [1-3]. In the midst of these developments, Japan has also begun promoting Society 5.0, an effort to create a human-centered society that achieves both economic development and solutions to social issues through a system that highly integrates virtual and real spaces [4]. Smart cities are attracting increasing attention as places where such concepts can be realized in Japan $[5,6]$.

While this movement is gaining momentum, there are still major issues surrounding the implementation of smart cities that must be addressed. The social acceptance of personal data collection and utilization is one such issue. In general, when a new technology is introduced in a particular region, conflicts of opinion tend to arise between citizens and the local government or company leading the project, and sufficient social acceptance is often not ensured [7-9]. For instance, the Sidewalk Labs project in Toronto, Canada, was a plan to develop the waterfront area on a large scale and utilize the data collected in facilities throughout the city [10]. However, when it became clear that the plan was to install sensors in many places and acquire a lot of personal information (such as the location of smartphones), which would be commercialized, the project faced strong opposition from citizens and became a social problem, which eventually led to its cancelation [11-14]. 
Capturing personal information relating to the travel routes, lifestyle habits, income, cell phone browsing history, and medical profiles of citizens is a typical aspect of smart cities [15-18]. In other words, issues related to privacy protection are closely related to the implementation of smart cities, not only in Toronto, but also all over the world, including Japan $[19,20]$. As noted in the example above, the perceived risk of leakage and abuse of a large amount of personal information may have a strong influence on the social acceptance of collecting and utilizing personal information in smart cities.

\subsection{Previous Studies Related to Social Acceptance}

To examine the determinants of the social acceptance of collecting and utilizing personal information in smart cities, it is useful to refer to the technology acceptance model (TAM), which deals with the social acceptance of scientific technology in general [21]. The TAM suggests that the perceived ease of use and usefulness of technology define behavioral intention to use and attitudes toward the use of technology, which influence actual behavior in using the technology [21]. A number of studies have attempted to extend the theory of the TAM, and one previous study found that the perceived ease of use and usefulness of technology are influenced by the perception of technological compatibility and trust in technology [22]. Another study has shown that trust influences behavioral intention to use technology through the mediation of reduced risk perception [23].

Other studies have examined the determinants of the social acceptance of a particular type of scientific technology. For example, in the implementation of wind power facilities, social acceptance was shown to be affected by perceived risk, benefit to the effort ratio, trust in local governments and companies, distributive justice (the perception of fairness to the outcome of the distribution), and procedural justice (the perception of fairness in the distribution procedure) [9]. In addition, many previous studies have identified trust in local governments and companies and the perceived necessity of technology as factors that influence the social acceptance of renewable energy technologies [24-28]. Trust has also been reported to be strongly associated with perceived justice $[29,30]$.

\subsection{Purpose and Overview}

Although these findings have been obtained, there are no studies that examining how each of the aforementioned factors relates to the social acceptance of collecting and utilizing personal information in smart cities. In addition, it has not been sufficiently examined whether the findings of TAM, which deals with scientific technology in general, and other studies that deal with a particular type of scientific technology can be applied in the context of smart cities.

In order to implement smart city projects more smoothly, it is important to organize the factors related to social acceptance. The theoretical significance of this research is combined with its practical value in highlighting important issues that local governments and companies should consider when they implement smart cities involving a collection and utilization of personal information from the general public. The novelty of this study is that it examines a model of the social acceptance of collecting and utilizing personal information in smart cities that incorporates a wide range of factors such as trust and perceptions of risk, justice, benefit, and necessity. Although these factors were investigated separately in previous research, we consider them in this study.

This study presented participants with a vignette of a smart city project and measured their social acceptance of collecting and utilizing personal information, trust, and perceptions of the risk, justice, benefit, and necessity of the project. In particular, previous research on risk perception has considered two separate variables: perception of the probability of risks (the likelihood of a certain damaging event occurring) and perception of the size of risks (the degree of damage that would be incurred if a certain event occurred) [31,32]. Hence, in this study, we deal with these variables separately, and examine in detail the effects of perceived risk on social acceptance. With reference to a number of previous studies, including the TAM $[9,21-30]$, we examine a model in which perceived justice 
influences trust and trust influences social acceptance through the mediation of perceived risk, benefit, and necessity.

\section{Materials and Methods}

\subsection{Methodology}

We conducted an online survey in November 2020 and examined an appropriate model to describe the relationship between various factors quantitatively. Specifically, we conducted structural equation modeling to examine a model in which perceived justice influences trust and trust influences social acceptance through the mediation of perceived risk, benefit, and necessity. The participants' age and gender were controlled.

\subsection{Participants}

We commissioned a research company (Cross Marketing, Inc., Tokyo, Japan) to recruit participants. A total of 568 Japanese citizens ( 283 males and 285 females) between 18 and 82 years of age participated in the study. Participants were recruited from all over Japan without any considerable bias in age, gender, or region of residence. Before data screening, the mean age of all participants was 45.27 years $(S D=15.02)$. This study was approved by the ethics committee of the University of Tokyo.

\subsection{Vignette}

The vignette was created by referring to the case of a smart city project planned for implementation in Toronto, which involved collecting and utilizing personal information [10-14]. The full vignette can be found in Appendix A. Specifically, the vignette included descriptions of how a local government (of "Area B" in "City A") and a company ("Company C") would lead the implementation of a smart city, the content of personal information that would be captured in the project, the manner in which this information would be used, concerns relating to the potential leakage of personal information, and how the company would respond to these concerns.

\subsection{Items}

With the exception of demographic items (age, gender, and nationality), all items were evaluated using a six-point Likert scale, with higher scores indicating a stronger degree of agreement with each. For the following variables, a list of items was provided in the Open Science Framework (OSF) (https:/ / osf.io/b7jt5/ accessed on 15 August 2021) (see supplementary materials).

Social acceptance was measured using two items $(r=0.87, p<0.001)$ ("Assuming you live in Area B, and you think this project is good for you", and "Assuming you live in Area $B$, and you want to help with this effort as a resident") [33]. Perceived risk was measured using a single item of probability of risks ("When you provide personal information for this project, how likely do you think it is that your personal information will be leaked?") and a single item of size of risks ("How much damage do you think people will suffer if the personal information provided for this project is leaked?") [32,34]. Perceived justice was measured using three items of procedural justice $(\alpha=0.86)$ ("Do you think that City A has adopted a fair approach in deciding to implement this project?"; "Do you think that City A is sufficiently listening to the opinions of its residents in implementing this project?"; and "Do you think that City A has provided sufficient explanation to the residents in implementing this project?"), and a single item of distributional justice ("Do you think that City A will treat all residents equally in the process of implementing this project?") [35-37]. Trust was measured using a single item of trust in the city government ("How much do you trust City A to implement this project?") and a single item of trust in the company ("How much do you trust Company $\mathrm{C}$ to implement this project?") [9]. Perceived benefit was measured using three items of benefit for self $(\alpha=0.87)$ ("Assuming you live in Area B, this project will improve your standard of living"; "Assuming you live in Area B, this project will have a positive impact on you"; and "Assuming you live in Area B, this project 
will make your life safer") and using three items of benefit for all citizens $(\alpha=0.86)$ ("This project will improve the standard of living for the entire citizens"; "This project will have a positive impact on the entire citizens"; and "This project will make the life safer for all citizens") [33]. Perceived necessity was measured using a single item ("Do you think that this project is highly necessary for citizens?").

\subsection{Procedure and Analysis}

The survey was conducted online. Participants were briefed on the study, and then required to indicate their agreement to participate and respond to each of the demographic items. Later, they were asked to read a vignette of a smart city. The instruction was, "Assume that the government where you live is implementing this project". We did not set a time limit for reading the vignette but told them to move on to the next page once they had fully understood the content. Participants then responded to each of the following items: social acceptance, trust, and perceived risk, justice, benefit, and necessity. The vignette was always displayed at the top of the screen, and participants were able to view it while providing their responses to each of the items.

The statistical software $R$ (ver. 4.1.0) was used for the analysis. The statistical significance level was set at $\alpha=0.05$. The data and $\mathrm{R}$ scripts used in the analysis were posted on the OSF.

\section{Results}

\subsection{Screening}

Participants who failed to select "agree" in response to the item "Please select 'agree' for this item" $(N=143)$ were excluded from the analysis. As a result of this screening, the data used in the analysis were $N=425$ (199 males and 226 females between 18 and 82 years of age). The mean age of participants was 46.77 years $(S D=15.21)$. We did not measure details such as the location and cultural background of each participant. The limitations due to this lack of measurement are discussed later. The means, standard deviations, and correlation coefficients for each variable are listed in Table 1.

Table 1. Means, standard deviations, and correlation coefficients for each variable.

\begin{tabular}{ccccccccccccc}
\hline & & $\boldsymbol{M}$ & SD & $\mathbf{1}$ & $\mathbf{2}$ & $\mathbf{3}$ & $\mathbf{4}$ & $\mathbf{5}$ & $\mathbf{6}$ & $\mathbf{7}$ & $\mathbf{8}$ & $\mathbf{9}$ \\
\hline 1 & Soc-A & 3.20 & 1.17 & - & & & & & & & & \\
2 & Ris-P & 3.98 & 1.01 & -0.33 & - & & & & & & \\
3 & Ris-S & 4.15 & 1.06 & -0.30 & 0.47 & - & & & & & \\
4 & Jus-P & 3.07 & 0.92 & 0.61 & -0.40 & -0.28 & - & & & & \\
5 & Jus-D & 3.23 & 1.10 & 0.49 & -0.34 & -0.28 & 0.72 & - & & & & \\
6 & Tru-Ci & 3.24 & 1.02 & 0.67 & -0.38 & -0.29 & 0.63 & 0.49 & - & & & \\
7 & Tru-Co & 3.01 & 1.05 & 0.69 & -0.43 & -0.36 & 0.65 & 0.51 & 0.75 & - & & \\
8 & Ben-S & 3.45 & 0.95 & 0.65 & -0.32 & -0.19 & 0.69 & 0.54 & 0.63 & 0.59 & - & \\
9 & Ben-A & 3.52 & 0.93 & 0.63 & -0.30 & -0.21 & 0.67 & 0.56 & 0.60 & 0.57 & 0.86 & - \\
10 & Nec & 3.11 & 1.05 & 0.61 & -0.32 & -0.25 & 0.69 & 0.52 & 0.54 & 0.54 & 0.66 & 0.68 \\
\hline
\end{tabular}

Soc-A: social acceptance; Ris-P: probability of risks; Ris-S: size of risks; Jus-P: procedural justice; Jus-D: Distributional justice; Tru-Ci: Trust in the city government; Tru-Co: Trust in the company; Ben-S: Benefit for self; Ben-A: Benefit for all citizens; Nec: Necessity. All correlation coefficients were $p<0.001$.

\subsection{Structural Equation Modeling}

We conducted structural equation modeling to examine the model in which perceived justice influences trust and trust influences social acceptance through the mediation of perceived risk, benefit, and necessity (Model 1). The participants' age and gender were controlled. The goodness of fit for Model 1 was not satisfactory (RMSEA $=0.12$, AGFI $=0.74$, CFI $=0.94$ ) (Figure 1). Therefore, we examined Model 2, which includes a path in which perceived justice predicts perceived risk, benefit, and necessity, and perceived benefit and perceived necessity are covariates. Although the goodness of fit improved for Model 2 $(\mathrm{RMSEA}=0.08, \mathrm{AGFI}=0.87, \mathrm{CFI}=0.97)$, it was not sufficient (Figure 2 ). Therefore, we 
added a path in which trust directly predicted social acceptance (Model 3). The goodness of fit for Model 3 was determined to be adequate (RMSEA $=0.04$, AGFI $=0.94, \mathrm{CFI}=0.99$ ) (Figure 3).

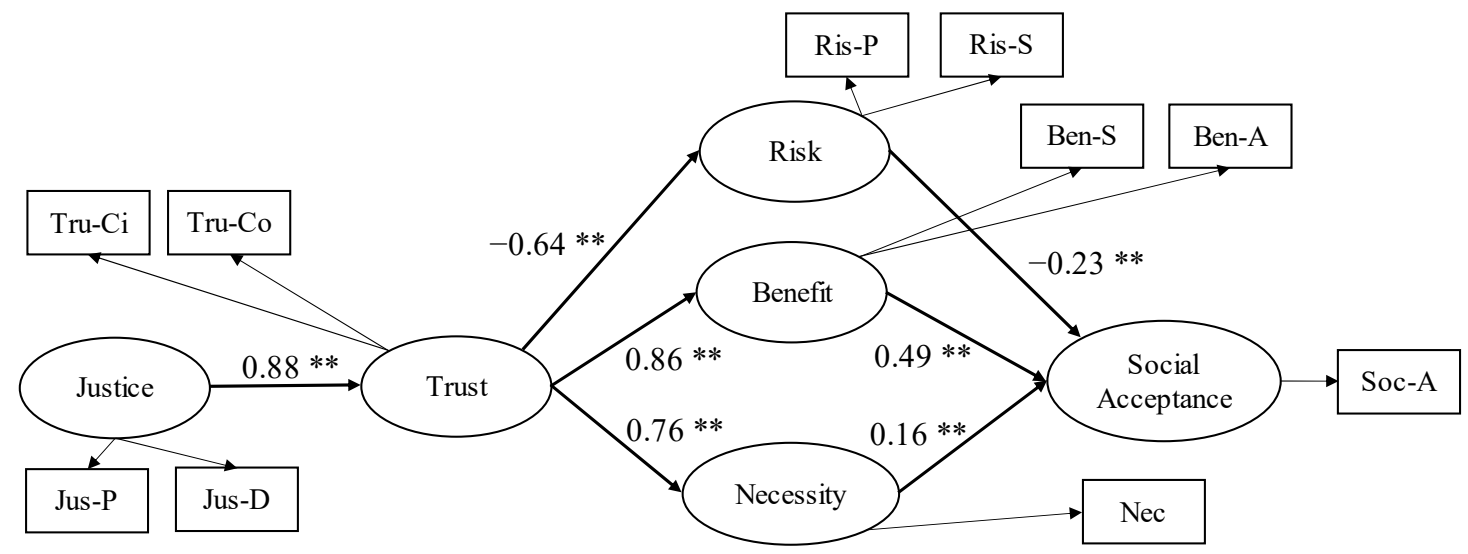

Figure 1. Results of Model 1. Coefficients are standardized and all coefficients of measurement equations are significant $(\beta>0.61, p<0.001)$. Soc-A: Social acceptance, Ris-P: Probability of risks, Ris-S: Size of risks, Jus-P: Procedural justice, Jus-D: Distributional justice, Tru-Ci: Trust in the city government, Tru-Co: Trust in the company, Ben-S: Benefit for self, Ben-A: Benefit for all citizens, Nec: Necessity. ${ }^{* *} p<0.01$.

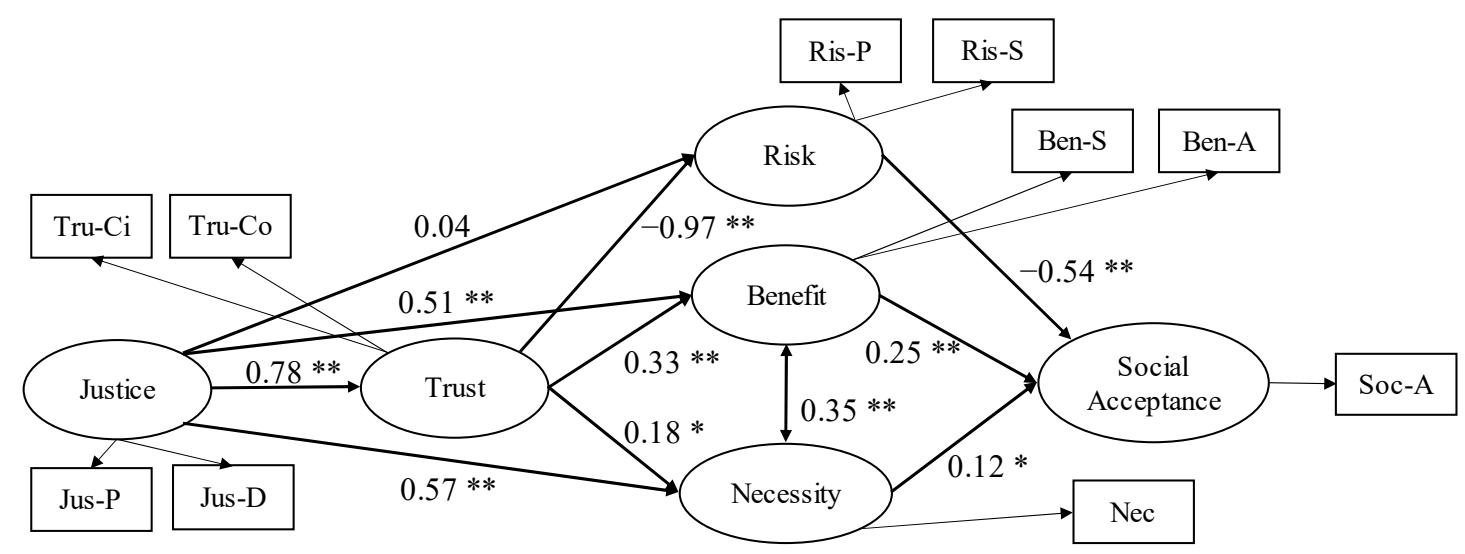

Figure 2. Results of Model 2. Coefficients are standardized and all coefficients of measurement equations are significant $(\beta>0.44, p<0.001)$. ${ }^{*} p<0.05,{ }^{* *} p<0.01$.

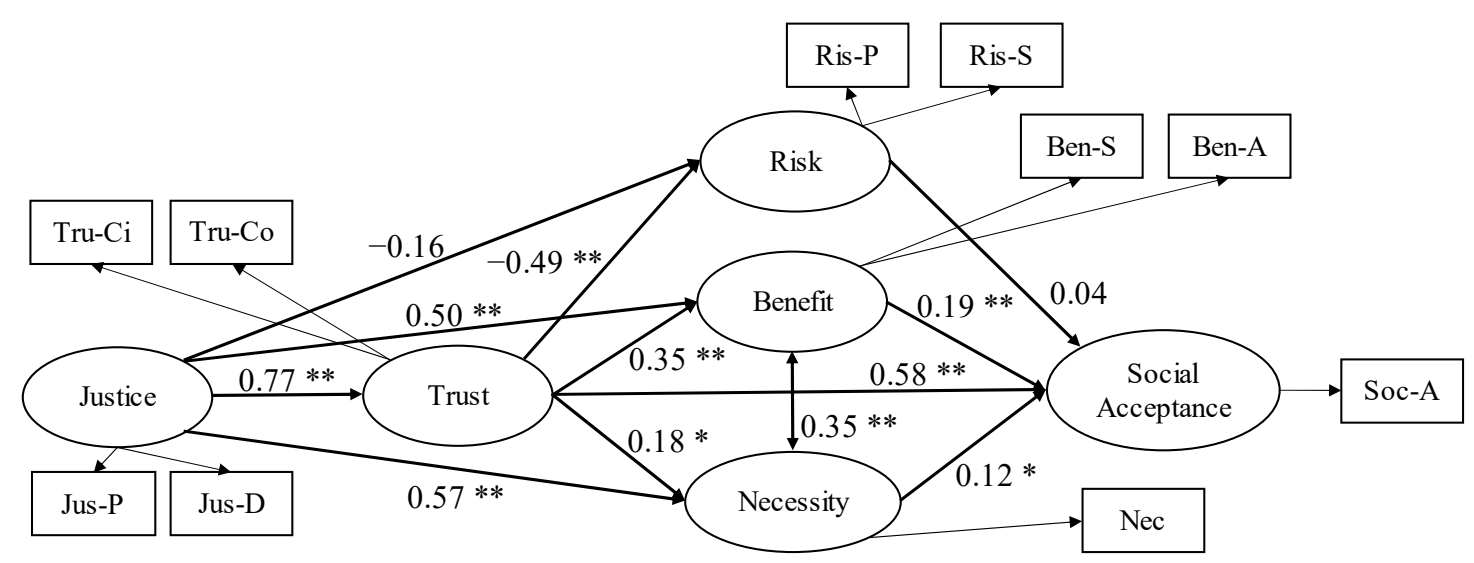

Figure 3. Results of Model 3. Coefficients are standardized and all coefficients of measurement equations are significant $(\beta>0.60, p<0.001) .{ }^{*} p<0.05,{ }^{* *} p<0.01$. 


\section{Discussion}

In this study, we examined a model of the social acceptance of collecting and utilizing citizens' personal information in smart cities, focusing on a wide range of factors such as trust and perceptions of risk, justice, benefit, and necessity. Our findings showed that trust was positively related to perceived justice, but negatively related to perceived risk. Trust was also shown to have a positive relationship with perceived benefit and perceived necessity. In addition, social acceptance was positively related to trust, perceived benefit, and perceived necessity.

\subsection{Various Factors Related to the Social Acceptance of Collecting and Utilizing Personal Information in Smart Cities}

The social acceptance of collecting and utilizing personal information in smart cities was found to be positively related to trust, perceived benefit, and perceived necessity, which is consistent with the TAM that deals with the social acceptance of scientific technology in general [21-23]. Our results were also consistent with those of previous studies that examined the social acceptance of specific technologies such as renewable energy $[9,24-30]$. In particular, trust was found to have not only a direct effect on social acceptance, but also an indirect effect mediated by perceived benefit and perceived necessity. Therefore, it may be suggested that trust is an especially important factor that influences the social acceptance of smart cities. It was also found that it is important to gain the initial trust of citizens in the implementation of scientific technology [38-40]. Hence, in future research, it will be necessary to consider the fact that trust is a variable that changes over time [41]. For example, longitudinal as well as pre- and post-design studies are needed to examine changes in trust. These efforts will be useful in understanding in more detail how to increase the social acceptance of smart cities.

Perceived justice was also found to have a strong positive relationship with trust, in concordance with previous studies $[29,30]$. Furthermore, there was an indirect effect on social acceptance mediated by trust, perceived benefit, and perceived necessity. For this reason, it is important to continue to examine the impact of perceived justice on the social acceptance of smart cities [9]. To increase the social acceptance of collecting and utilizing personal information in smart cities, it would be effective for local governments and companies to review and improve the level of trust placed in them by citizens, and their ability to prepare plans based on fair procedures (i.e., in accordance with the principles of procedural justice) and ensure that services are provided equally to all citizens (i.e., distributional justice).

While perceived risk was not found to have a significant effect on social acceptance in this study, many previous studies have shown that perceived risk is negatively related to social acceptance $[9,42,43]$. One of the reasons for such a departure from the findings of previous studies is that perceived risk and trust were observed to have a strong negative relationship in this study (as seen in Figure 3). In addition, Model 2, which excludes the path of the direct effect of trust on social acceptance in Model 3, shows a significant negative effect of perceived risk on social acceptance (Figure 2). In light of this, it is possible that the items used in this study did not strictly distinguish between trust and perceived risk, and the influence of perceived risk on social acceptance should continue to be examined. As mentioned in the introduction, another possible reason for the failure of the implementation of the smart city in Toronto [10-14] is that it could not gain sufficient social acceptance of collecting and utilizing personal information due to the high perceived risk of the way personal information is handled, as well as the low trust in the leading companies.

\subsection{Limitations}

Although the above findings were obtained in this study, there are two major limitations. First, we were unable to examine the perceived ease of use of each technology as a factor that could affect the social acceptance of smart cities. This study examined a model of social acceptance focusing on the aspect of personal information acquired in smart cities 
and the leakage of such information. On the contrary, many new scientific technologies are expected to have desirable effects in smart cities, and the perceived ease of use of each technology may affect social acceptance [21,22]. Although it is difficult to exhaustively examine all the relevant factors that influence the social acceptance of smart cities, it is necessary to extend our model by referring to previous studies that examined the social acceptance of various scientific technologies. Second, we did not adequately measure the participants' regions of residence and cultural backgrounds. Depending on these characteristics, various factors such as participants' attitudes toward smart cities may differ. In addition, participants in this study were limited to Japanese people. Some previous studies suggested that there are cultural differences in accepting attitudes toward scientific technology [44-46]. Since most previous research in this literature has been conducted in the United States and Europe, it will be necessary to consider the impact of cultural differences when comparing the findings of this study with those of previous studies.

\section{Conclusions}

Despite these limitations, this study validated a model of the social acceptance of collecting and utilizing personal information in smart cities. The results suggest that trust, perceived benefit, and perceived necessity have a significant influence on social acceptance. We believe that this knowledge will contribute to practical efforts in smart city projects aimed at increasing the social acceptance of collecting and utilizing personal information. For example, it has been pointed out that it is important for local governments and companies to provide, in a proactive manner, opportunities for consultation with citizens to increase social acceptance [8], which in turn will lead to increased trust among citizens. Under these conditions, it will be effective to promote the benefits and necessity of the project. Additionally, citizen engagement is one of the characteristic elements of smart cities [1]. Specifically, it has been suggested that the perceived extent to which citizens are involved in the formulation and implementation of urban planning may affect citizens' satisfaction [47-49]. Therefore, it would also be meaningful to examine the relationship between the degree of citizen engagement and the social acceptance of smart cities [50]. In today's world, as smart city implementations continue to gain momentum, the issue of social acceptance cannot be avoided. Further refinement of the model presented in this study and its application to practical initiatives will be required in future research.

Supplementary Materials: Supplementary materials are available online at OSF (https:/ / osf.io/b7 jt5/ accessed on 15 August 2021).

Author Contributions: Conceptualization, Y.S., S.O., T.H. and K.K.; methodology, Y.S.; validation, Y.S.; formal analysis, Y.S. and T.H.; investigation, Y.S. and S.O.; writing-original draft preparation, Y.S.; writing-review and editing, S.O., T.H. and K.K.; project administration, S.O. and K.K.; funding acquisition, S.O. and K.K. All authors have read and agreed to the published version of the manuscript.

Funding: This research was supported by the Hitachi and UTokyo Joint Research.

Institutional Review Board Statement: The study was conducted according to the guidelines of the Declaration of Helsinki and approved by the Ethics Committee of the University of Tokyo (UTSP-20026; 14 November 2020).

Informed Consent Statement: Informed consent was obtained from all subjects involved in the study.

Data Availability Statement: The data presented in this study are openly available in the OSF (https:/ / osf.io/b7jt5/ accessed on 15 August 2021).

Acknowledgments: This research is a substantially revised version of a graduation thesis submitted by Keita Ito to the Faculty of Letters, University of Tokyo, in the year 2020. We would like to express our gratitude for the many ways in which he has contributed to the preliminary conception and implementation of this study. We would also like to express our sincere thanks to Mitsuharu Tai of R\&D Group, Hitachi, Ltd. for his helpful feedback and comments on the manuscript. 
Conflicts of Interest: The authors declare no conflict of interest.

\section{Appendix A. Vignette}

One city, "City A" is working on a smart city plan to collect various data in "Area B" within that city and use this data to create a better quality of life for residents and a more sustainable environment. City A manages the data collected in Area B and commissions a well-known "Company $C$ " to analyze them. Company $C$ proposes crime prevention and environmental measures based on the analysis results.

In Area B, each individual will be identified by cameras installed on streetlights, which will be used to provide information tailored to each individual's mode of behavior and to track criminals.

Company $\mathrm{C}$, on the other hand, is in the business of using data to infer the needs of residents and provide it to other companies. Therefore, concerns have been expressed that the data from Area B will also be provided to other companies, leading to the leakage of personal information.

In response to this concern, Company $\mathrm{C}$ made the following comment: "It is possible that processed data, which has been processed so that individuals cannot be identified, may be sold for new services. This is not a legal issue, and we promise to set up an internal review committee of experts and employees to make an informed decision. In addition, with current technology, it is unlikely that an individual will be identified using this data."

\section{References}

1. Granier, B.; Kudo, H. How are citizens involved in smart cities? Analysing citizen participation in Japanese "Smart Communities". Sci. Inf. Policy 2016, 21, 61-76. [CrossRef]

2. Khansari, N.; Mostashari, A.; Mansouri, M. Impacting sustainable behavior and planning in smart city. Int. J. Sustain. Land Use Urban Plan. 2013, 1, 46-61. [CrossRef]

3. Neirotti, P.; De Marco, A.; Cagliano, A.C.; Mangano, G.; Scorrano, F. Current trends in smart city initiatives: Some stylised facts. Cities 2014, 38, 25-36. [CrossRef]

4. Japan Cabinet Office. Society 5.0. 2021. Available online: https://www8.cao.go.jp/cstp/society5_0/index.html (accessed on 14 August 2021).

5. Japan Cabinet Office. Toward the Promotion of Smart Cities. 2020. Available online: https://www5.cao.go.jp/keizai-shimon/ kaigi/special/reform/wg6/20201029/pdf/shiryou1.pdf (accessed on 14 August 2021).

6. Gurjanov, A.V.; Zakoldaev, D.A.; Shukalov, A.V.; Zharinov, I.O. The smart city technology in the super-intellectual Society 5.0. J. Phys. Conf. Ser. 2020, 1679, 032029. [CrossRef]

7. Baba, K.; Kimura, O.; Suzuki, T. Social decision making process to address environmental disputes on wind farm siting. Sociotechnica 2005, 3, 241-258. [CrossRef]

8. Soma, K.; Haggett, C. Enhancing social acceptance in marine governance in Europe. Ocean. Coast. Manag. 2015, 117, 61-69. [CrossRef]

9. Sonnberger, M.; Ruddat, M. Local and socio-political acceptance of wind farms in Germany. Technol. Soc. 2017, 51, 56-65. [CrossRef]

10. Tenney, M.; Garnett, R.; Wylie, B. A theatre of machines: Automata circuses and digital bread in the smart city of Toronto. Can. Geogr. 2020, 64, 388-401. [CrossRef]

11. Keymolen, E.; Voorwinden, A. Can we negotiate? Trust and the rule of law in the smart city paradigm. Int. Rev. Law Comput. Technol. 2020, 34, 233-253. [CrossRef]

12. Artyushina, A. Is civic data governance the key to democratic smart cities? The role of the urban data trust in sidewalk Toronto. Telemat. Inform. 2020, 55, 101456. [CrossRef]

13. Mann, M.; Mitchell, P.; Foth, M.; Anastasiu, I. \#BlockSidewalk to Barcelona: Technological sovereignty and the social license to operate smart cities. J. Assoc. Inf. Sci. Technol. 2020, 71, 1103-1115. [CrossRef]

14. Sands, G.; Filion, P.; Reese, L.A. Techs and the cities: A new economic development paradigm? Urban Plan. 2020, 5, 392-402. [CrossRef]

15. Al-Azzam, M.; Alazzam, M.B. Smart city and smart-health framework, challenges and opportunities. Int. J. Adv. Comput. Sci. Appl. 2019, 10, 171-176. [CrossRef]

16. Baldini, G.; Kounelis, I.; Fovino, I.N.; Neisse, R. A framework for privacy protection and usage control of personal data in a smart city scenario. In Critical Information Infrastructures Security; Luiijf, E., Hartel, P., Eds.; Springer: Cham, Switzerland, 2013; pp. 212-217. [CrossRef]

17. Syerov, Y.; Shakhovska, N.; Fedushko, S. Method of the data adequacy determination of personal medical profiles. Adv. Artif. Syst. Med. Educ. II 2019, 902, 333-343. [CrossRef] 
18. Rahman, M.A.; Hossain, M.S.; Showail, A.J.; Alrajeh, N.A.; Alhamid, M.F. A Secure, private, and explainable IoHT framework to support sustainable health monitoring in a smart city. Sustain. Cities Soc. 2021, 72, 103083. [CrossRef]

19. Ståhlbröst, A.; Padyab, A.; Sällström, A.; Hollosi, D. Design of smart city systems from a privacy perspective. IADIS Int. J. WWW/Internet 2015, 13, 1-16.

20. Yang, L.; Elisa, N.; Eliot, N. Privacy and security aspects of E-government in smart cities. In Smart Cities Cybersecurity and Privacy; Rawat, D.B., Ghafoor, K.Z., Eds.; Elsevier: Amsterdam, The Netherlands, 2019; pp. 89-102. [CrossRef]

21. Davis, F.D.; Bagozzi, R.P.; Warshaw, P.R. User acceptance of computer technology: A comparison of two theoretical models. Manag. Sci. 1989, 35, 982-1003. [CrossRef]

22. Ghazizadeh, M.; Lee, J.D.; Boyle, L.N. Extending the technology acceptance model to assess automation. Cogn. Technol. Work. 2012, 14, 39-49. [CrossRef]

23. Choi, J.K.; Ji, Y.G. Investigating the importance of trust on adopting an autonomous vehicle. Int. J. Hum.-Comput. Interact. 2015, 31, 692-702. [CrossRef]

24. Iliopoulos, N.; Esteban, M.; Kudo, S. Assessing the willingness of residential electricity consumers to adopt demand side management and distributed energy resources: A case study on the Japanese market. Energy Policy 2020, 137, 111169. [CrossRef]

25. Kim, Y.; Lee, J.; Ahn, J. Innovation towards sustainable technologies: A socio-technical perspective on accelerating transition to aviation biofuel. Technol. Forecast. Soc. Chang. 2019, 145, 317-329. [CrossRef]

26. Stigka, E.K.; Paravantis, J.A.; Mihalakakou, G.K. Social acceptance of renewable energy sources: A review of contingent valuation applications. Renew. Sustain. Energy Rev. 2014, 32, 100-106. [CrossRef]

27. Walter, J. Technological adaptation and "learning by cooperation": A case study of a successful onshore technology transfer in Tierra del Fuego. J. Technol. Transf. 2000, 25, 13-22. [CrossRef]

28. Wüstenhagen, R.; Wolsink, M.; Bürer, M.J. Social acceptance of renewable energy innovation: An introduction to the concept. Energy Policy 2007, 35, 2683-2691. [CrossRef]

29. Goedkoop, F.; Devine-Wright, P. Partnership or placation? The role of trust and justice in the shared ownership of renewable energy projects. Energy Res. Soc. Sci. 2016, 17, 135-146. [CrossRef]

30. Huijts, N.M.; Molin, E.J.; Steg, L. Psychological factors influencing sustainable energy technology acceptance: A review-based comprehensive framework. Renew. Sustain. Energy Rev. 2012, 16, 525-531. [CrossRef]

31. Beck, K.H. The effects of risk probability, outcome severity, efficacy of protection and access to protection on decision making: A further test of protection motivation theory. Soc. Behav. Personal. 1984, 12, 121-125. [CrossRef]

32. Gerber, N.; Reinheimer, B.; Volkamer, M. Investigating people's privacy risk perception. Proc. Priv. Enhancing Technol. 2019, 3 , 267-288. [CrossRef]

33. Hashimoto, T.; Tham, Y.J.; Karasawa, K.; Tai, M. Understanding people's attitudes toward a "data-driven" society based on trust and technology acceptance models. In Proceedings of the 84th Annual Convention of the Japanese Psychological Association, Tokyo, Japan, 8 September-2 November 2020; p. PQ-003.

34. Krasnova, H.; Veltri, N.F. Privacy calculus on social networking sites: Explorative evidence from Germany and USA. In Proceedings of the 43rd Hawaii International Conference on System Sciences, Honolulu, HI, USA, 5-8 January 2010; pp. 1-10. [CrossRef]

35. Ohbuchi, K.; Fukuno, M. The justice-bond hypothesis and people's attitude toward Japanese society: Multi-level evaluation of distributive and procedural justice. Jpn. J. Soc. Psychol. 2003, 18, 204-212. [CrossRef]

36. Takao, K. Perceived procedural fairness and the evaluation of authorities: A case of an urban development project. Jpn. J. Soc. Psychol. 2002, 17, 136-140. [CrossRef]

37. Takenishi, M.; Takenishi, A. Group-value and self-value of procedural justice: Examining the social identity mediation model on group-oriented behaviors and self-esteem. Jpn. J. Soc. Psychol. 2006, 22, 198-220. [CrossRef]

38. Kim, G.; Shin, B.; Lee, H.G. Understanding dynamics between initial trust and usage intentions of mobile banking. Inf. Syst. J. 2009, 19, 283-311. [CrossRef]

39. Zhang, T.; Tao, D.; Qu, X.; Zhang, X.; Lin, R.; Zhang, W. The roles of initial trust and perceived risk in public's acceptance of automated vehicles. Transp. Res. Part C Emerg. Technol. 2019, 98, 207-220. [CrossRef]

40. Nguyen, T.; Hoang, D.; Seneviratne, A. Exploring challenge-response mechanism designs for IoT initial trust establishment. In Proceedings of the 2018 IEEE International Conference on Communications Workshops, Kansas City, MO, USA, 20-24 May 2018; pp. 1-6.

41. McKnight, D.H.; Cummings, L.L.; Chervany, N.L. Initial trust formation in new organizational relationships. Acad. Manag. Rev. 1998, 23, 473-490. [CrossRef]

42. Pavlou, P.A. Consumer acceptance of electronic commerce: Integrating trust and risk with the technology acceptance model. Int. J. Electron. Commer. 2003, 7, 101-134. [CrossRef]

43. Siegrist, M. The influence of trust and perceptions of risks and benefits on the acceptance of gene technology. Risk Anal. 2000, 20, 195-203. [CrossRef]

44. Sawng, Y.W.; Lee, J.; Motohashi, K. Digital convergence service from the viewpoint of provider and user factors using technology acceptance and diffusion model. Clust. Comput. 2015, 18, 293-308. [CrossRef]

45. Srite, M. Culture as an explanation of technology acceptance differences: An empirical investigation of Chinese and US users. Australas. J. Inf. Syst. 2006, 14, 5-26. [CrossRef] 
46. Sun, S.; Lee, P.; Law, R. Impact of cultural values on technology acceptance and technology readiness. Int. J. Hosp. Manag. 2019, 77, 89-96. [CrossRef]

47. Liebe, U.; Preisendörfer, P.; Enzler, H.B. The social acceptance of airport expansion scenarios: A factorial survey experiment. Transp. Res. Part D Transp. Environ. 2020, 84, 102363. [CrossRef]

48. Rowe, G.; Frewer, L.J. A typology of public engagement mechanisms. Sci. Technol. Hum. Values 2005, 30, 251-290. [CrossRef]

49. Wolsink, M. The research agenda on social acceptance of distributed generation in smart grids: Renewable as common pool resources. Renew. Sustain. Energy Rev. 2012, 16, 822-835. [CrossRef]

50. Choque, J.; Diez, L.; Medela, A.; Muñoz, L. Experimentation management in the co-created smart-city: Incentivization and citizen engagement. Sensors 2019, 19, 411. [CrossRef] [PubMed] 